\section{headspace - Australia's innovation in youth mental health: who are the clients and why are they presenting?}

To THE EDITOR: The study by Rickwood and colleagues ${ }^{1}$ of aggregated national data for young people attending headspace centres is most welcome, as we can now compare headspace with other pre-existing and current datasets. In 2001, we reported on mental health services provided during 46515 consultations by 386 general practitioners (mean patient age, 46 years; $34 \%$ male). ${ }^{2}$ At the time, we noted that being aged under 25 years was associated with unmet need for both threshold (odds ratio, 1.34) and subthreshold mental disorders (odds ratio, 1.94-2.11). ${ }^{3}$ We concluded that young people with mental disorders were particularly poorly served by general practice. ${ }^{4}$ While these data informed subsequent development of youth-specific services, we did not specifically report data for people aged under 25 years. Of these participants, 3503/5868 self-reported a significant mental health problem. Consequently, we can compare directly our 2001 cohort $^{2,3}$ with that of the new aggregated headspace cohort. ${ }^{1}$ At this stage, it would appear that only small differences are evident (2001 v 2013, respectively: male, 27\% v $36 \%$; born overseas, $12 \%$ v $7 \%$; Aboriginal and Torres Strait Islander descent, $5 \% \mathrm{v} 8 \%$; living in major cities, $65 \%$ v 57\%; non-participation in employment or education, $36 \%$ v 29\%; and no days out of role, $41 \%$ v $36 \%)$. In a dataset collected between 2007 and 2009 from two urban headspace sites managed by the University of Sydney, we noted a more substantial engagement of young men (of 1260 participants, $53 \%$ were male) and comparable disability characteristics to the two other datasets (non-participation in employment or education, 30\%; no days out of role, $34 \%) .{ }^{5}$ In future reports from headspace nationally and locally, we look forward to presentation of other data that permit relevant comparative assessment and challenge us to design new services to meet known gaps.

Tracey A Davenport Research Affiliate Elizabeth M Scott Clinical Director of headspace Services Daniel F Hermens Senior Research Fellow Brain \& Mind Research Institute, University of Sydney, Sydney, NSW.

\section{tracey.davenport@sydney.edu.au}

Competing interests: Elizabeth Scott has received honoraria for educational seminars related to the clinical management of depressive disorders supported by Servier and Eli Lilly, and has participated in a Servier-sponsored multicentre trial of agomelatine for depressive disorders and on a national advisory board for desvenlafaxine, manufactured by Pfizer. Daniel Hermens has received honoraria for educational seminars from Janssen-Cilag, Eli Lilly and the New South Wales Institute of Psychiatry.

doi: 10.5694/mjal4.00123

1 Rickwood DJ, Telford NR, Parker AG, et al. headspace - Australia's innovation in youth mental health: who are the clients and why are they presenting? Med J Aust 2014; 200: 108-111.

2 Hickie IB, Davenport TA, Hadzi-Pavlovic D, et al. Development of a simple screening tool for common mental disorders in general practice. Med J Aust 2001; 175 (2 Suppl): S10-S17.

3 Hickie IB, Davenport TA, Scott EM, et al. Unmet need for recognition of common mental disorders in Australian general practice. Med $\rfloor$ Aust 2001; 175 (2 Suppl): S18-S24.

4 Hickie IB, Davenport TA, Naismith SL, Scott EM. Conclusions about the assessment and management of common mental disorders in Australian general practice. SPHERE National Secretariat. Med J Aust 2001; 175 (2 Suppl): S52-S55.

5 Scott EM, Hermens DF, Glozier N, et al. Targeted primary care-based mental health services for young Australians. Med J Aust 2012; 196: 136-140.

To THE Editor: We commend Rickwood and colleagues ${ }^{1}$ for presenting aggregated data from headspace centres. However, to judge whether headspace is meeting its key policy objectives, more detailed information is required. No performance benchmarks were proposed for the national program or for the constituent centres. Specifically, the variance in key characteristics (age, sex, Aboriginal and Torres Strait Islander populations, rurality, socioeconomic status and current disability) of young people attending the individual centres was not described. As headspace centres were initially placed in areas of need (ie, non-urban, low socioeconomic status, fewer private medical or psychological services, or high Aboriginal and Torres Strait Islander populations), one might expect to see evidence of enhanced access for those with disability or financial hardship. For example, at the University of Sydney-managed headspace sites, $25 \%$ of young people were receiving financial assistance and "the same fraction (were) completely disconnected from employment or education" (emphasis added). ${ }^{2}$ Internationally, youthtargeted mental health services are being encouraged to focus on such disadvantaged individuals. ${ }^{3}$ In Australia, $12 \%$ of youth are in this category, and the proportion varies significantly by geographical region $(7 \%-35 \%))^{4}$ These proportions are not the same as those reported by Rickwood et al ${ }^{1}$ (29\% in the headspace cohort and 27\% in the Australian population), where the measure used appears to be that of not participating fully in employment or education. Given that the economic and social justifications for early intervention are focused on enhancing such participation rates, ${ }^{5}$ clarification of the metrics being reported by headspace is essential.

other data [may] permit relevant comparative assessment

Davenport et al

Ian B Hickie Executive Director and Professor of Psychiatry, Brain \& Mind Research Institute

Elizabeth M Scott Clinical Director of headspace Services, Brain \& Mind Research Institute

Nicholas Glozier Professor of Psychiatry University of Sydney, Sydney, NSW.

ian.hickie@sydney.edu.au

Competing interests: Ian Hickie is a National Health and Medical Research Council Senior Principal Research Fellow and a National Mental Health Commissioner. He was a Director of headspace until 2012. He has led community-based and pharmaceutical industrysupported education programs related to anxiety, depression and psychosis. Current investigator-initiated studies in depression and circadian systems at the Brain \& Mind Research Institute are supported by Servier. He has received honoraria or travel support for participation in educational seminars related to depression, youth mental health or circadian rhythms research and clinical practice. Nicholas Glozier has served on an advisory board for Lundbeck and has received honoraria for presenting depression, sleep and functional-related presentations for Servier and Lundbeck.

doi: 10.5694/mjal4.00145

1 Rickwood DJ, Telford NR, Parker AG, et al. headspace - Australia's innovation in youth mental health: who are the clients and why are they presenting? Med J Aust 2014; 200: 108-111.

2 Scott EM, Hermens DF, Glozier N, et al. Targeted primary care-based mental health services 
for young Australians. Med J Aust 2012; 196 136-140.

3 Scott J, Fowler D, McGorry P, et al. Adolescents and young adults who are not in employment, education, or training. BMJ 2013; 347: f5270.

4 OECD. Education policy outlook: Australia. June 2013. http://www.oecd.org/edu/ EDUCATION\%20POLICY\%200UTLOOK\%20 AUSTRALIA_EN.pdf (accessed Apr 2014).

5 Hickie IB. Youth mental health: we know where we are and we can now say where we need to go next. Early Interv Psychiatry 2011; 5 Suppl 1: 63-69.

IN REPLY: Comparing data across different data collections is essential to advance knowledge. However, such comparisons are highly complex and require careful consideration of data item definitions, age ranges, population groups, time periods and data collection aims. Davenport and colleagues compare the aggregate data we reported for all headspace centre clients from early 2013 with data published from two Sydney centres collected between 2007 and 2009, and with general practice client data from people with self-reported significant mental health problems in 2001. The variance of the Sydney centres demonstrates the diversity among headspace centres, which were rolled out at different time points and responsive to a wide range of community contexts across Australia. ${ }^{1}$ Consequently, aggregate data provide just one small step in our understanding. With the capability enabled by the new headspace datacollection system implemented in 2013, describing the commonalities and differences between centres and identifying peer groups will be a priority. $^{2}$

In response to the request by Hickie and colleagues for clarification about engagement in education, employment and training — an increasingly important focus for youth services ${ }^{3}$ - the Box provides more detailed information relevant to youth unemployment using the full year's data for 2013 for headspace centres and comparing these with 2011 census data. This reveals a very high level of need for vocational assistance among young people when they first access headspace centres, as well as the variation in need across centres. Interpreting differences between the aggregate data and population level data and between centres demonstrates the challenges in data comparison.

Debra J Rickwood Professor of Psychology, ' and Chief Scientific Advisor, Evidence Building ${ }^{2}$

Nic R Telford Evaluation Manager ${ }^{2}$

Alexandra G Parker Director, Centre of Excellence ${ }^{2}$

\section{Chris J Tanti CEO ${ }^{2}$}

Patrick D McGorry Executive Director ${ }^{3}$

1 Faculty of Health, University of Canberra, Canberra, ACT. 2 headspace National Youth Mental Health Foundation, Melbourne, VIC

3 Orygen Youth Health Research Centre, University of Melbourne, Melbourne, VIC.

debra.rickwood@canberra.edu.au

Competing interests: No relevant disclosures. doi: 10.5694/mjal4.00276

1 McGorry PD, Tanti C, Stokes R, et al. headspace: Australia's National Youth Mental Health Foundation - where young minds come first. Med J Aust 2007; 187 (7 Suppl): S68-S70.

2 Rickwood DJ, Van Dyke N, Telford N. Innovation in youth mental health services in Australia: common characteristics across the first headspace centres. Early Interv Psychiatry 2013; Jul 4 [Epub ahead of print]. doi: 10.1111/eip.12071.

3 Scott J, Fowler D, McGorry P, et al. Adolescents and young adults who are not in employment, education, or training BMJ 2013: 347: f5270.

Proportion of young people aged 17-25 years not currently engaged in education, by employment category (2011 census* v 2013 headspace centre client data ${ }^{\dagger}$ )

headspace centres $(n=9922)$

\begin{tabular}{|c|c|c|c|}
\hline Category & $\begin{array}{c}\text { Census proportion } \\
\quad(n=1321950)\end{array}$ & Proportion & Range \\
\hline Employed full-time & $53.2 \%$ & $14.3 \%$ & $4.1 \%-52.3 \%$ \\
\hline Employed part-time & $18.2 \%$ & $23.0 \%$ & $11.0 \%-32.4 \%$ \\
\hline Employed away from work & $4.7 \%$ & Not asked & Not asked \\
\hline Unemployed looking for full-time work & $7.1 \%$ & $23.3 \%$ & $6.5 \%-38.8 \%$ \\
\hline Unemployed looking for part-time work & $1.5 \%$ & $20.8 \%$ & $5.8 \%-32.0 \%$ \\
\hline Not in labour force & $14.2 \%$ & $18.5 \%$ & $4.4 \%-52.2 \%$ \\
\hline Not stated & $0.9 \%$ & $0.1 \%$ & $0.2 \%-0.9 \%$ \\
\hline
\end{tabular}

\section{National guidelines for the management of absolute cardiovascular disease risk}

To THE EDIToR: Concerns have been raised that the national Guidelines for the management of absolute cardiovascular disease risk ${ }^{1}$ recommend combining an angiotensin-converting enzyme

ACE inhibitorinduced cough or angioedema does preclude the use of an ARB in the same patient

O'Callaghan et al (ACE) inhibitor with an angiotensin receptor blocker (ARB) for blood pressure reduction. ${ }^{2}$ Grenfell replied on behalf of the National Vascular Disease Prevention Alliance, stating that these agents are of the same pharmacological class ${ }^{3}$ and that the guidelines recommend using an agent from a different pharmacological class for second-line therapy. Therefore, he argued that the guidelines recommend "against prescribing" these agents in combination. ${ }^{3}$ This is incorrect.

ACE inhibitors and ARBs are different classes of drugs. ${ }^{4}$ ARBs specifically inhibit the angiotensin II type 1 receptor whereas ACE inhibitors block production of angiotensin II. ACE inhibitors also degrade peptides such as bradykinin and substance $\mathrm{P}$, which explains why cough and angioedema are frequently seen with ACE inhibitor therapy, but rarely with ARB therapy. This and other pharmacological differences have clinical implications. For example, ACE inhibitor-induced cough or angioedema does preclude the use of an ARB in the same patient. ${ }^{4}$ Similarly, one cannot assume these drug classes produce similar clinical outcomes in the absence of evidence.

Even if these drugs were of the same class, the current form of the guidelines only recommends which combination should be used for second-line therapy, not which combinations should be avoided. ${ }^{1}$ This is appropriate. Clinicians should not think ACE inhibitors and ARBs should never be combined. Rather, if the choice exists, a different combination should be chosen. Put another way, hypertension should not be inadequately treated just to avoid using this combination. ${ }^{4}$

Christopher J O'Callaghan Clinical Pharmacologist Pei Rong Clinical Pharmacology Registrar Min Y Goh Clinical Pharmacologist 
Austin Health, Melbourne, VIC

\section{Christopher.ocallaghan@austin.org.au}

Competing interests: No relevant disclosures. doi: 10.5694/mjal3.11162

1 National Vascular Disease Prevention Alliance. Guidelines for the management of absolute cardiovascular disease risk. Canberra: NVDPA 2012. http://strokefoundation.com.au/site/ media/AbsoluteCVD_GL_webready.pdf (accessed Aug 2013)

2 Usherwood T. National guidelines for the management of absolute cardiovascular disease risk. Med J Aust 2013; 199: 243-244.

3 Grenfell RD. National guidelines for the management of absolute cardiovascular disease risk. Med J Aust 2013; 199: 244.

4 Rossi S. Australian medicines handbook. Adelaide: $\mathrm{AMH}, 2013$.

\section{Psychotropics and challenging behaviour in people with intellectual disability}

To THE EDITOR: Hilmer and Gnjidic drew attention to the pharmacological management of behavioural problems in nursing home residents, and called for a reduction in inappropriate prescribing and the development of alternative management strategies. ${ }^{1}$ We extend these concerns to another vulnerable population - people with intellectual disability. Historically, this population is one of the most medicated groups in modern society.

About $30 \%$ of people with intellectual disability have a mental illness, but up to $60 \%$ are prescribed psychotropic medication to manage challenging behaviour. ${ }^{2}$ Challenging behaviour, a catch-all term describing aggression and other socially unacceptable behaviour, can isolate individuals and cause significant distress for individuals, families, carers and clinicians. No Australian guidelines address treatment of challenging behaviour in people with intellectual disability with psychotropics, but UK guidelines recommend the use of non-pharmaceutical interventions in the absence of a diagnosable mental illness. ${ }^{3}$

Diagnosing mental illness requires clear communication, which is challenging for people with cognitive and communication impairments. Also, clinicians may feel pressure from carers to medicate. As a result, psychotropic medication - often antipsychotics - may be prescribed on a hypothesis of efficacy, rather than a diagnosis of a psychotic disorder. Corresponding improvements in challenging behaviour may then be attributed to medication, rather than sedation.

Definitive evidence of the effectiveness of antipsychotics in mitigating challenging behaviour is lacking. A seminal trial published in The Lancet found that risperidone was no more useful than placebo in reducing aggression in people with intellectual disability. ${ }^{4}$ In contrast, evidence of serious side effects associated with these medications is clear. ${ }^{5}$ People with intellectual disability face a higher burden of disease than other Australians; any decision to risk these side effects for an unproven benefit must be taken with extreme caution.

Australia lags behind the United Kingdom, where experience with intellectual disability is recognised as an essential component of training for general practitioners and psychiatrists. The Royal Australian and New Zealand College of Psychiatrists recently established a special interest group in intellectual disability; while this is a positive step, limited training in the assessment and management of people with intellectual disability continues to compromise optimal treatment. We need guidelines to reduce prescribing of psychotropics to people with intellectual disability without a diagnosis of mental illness, and research in this area is urgently needed to support the development of evidence-based care.

\section{Niki S Edwards Senior Lecturer'}

\section{William Alexander Medical Student ${ }^{2}$}

Allyson Mutch Senior Lecturer ${ }^{3}$

1School of Public Health and Social Work, Queensland University of Technology, Brisbane, QLD.

2 School of Medicine, University of Queensland, Brisbane, QLD.

3 School of Population Health, University of Queensland, Brisbane, QLD.

\section{niki.edwards@qut.edu.au}

Competing interests: No relevant disclosures. doi: 10.5694/mjal3.11258

1 Hilmer SN, Gnjidic D. Rethinking psychotropics in nursing homes. Med J Aust 2013; 198: 77.

2 Tsiouris JA, Kim SY, Brown WT, et al. Prevalence of psychotropic drug use in adults with intellectual disability: positive and negative findings from a large scale study. J Autism Dev Disord 2013; 43: 719-731.

3 Deb S, Kwok H, Bertelli M, et al. International guide to prescribing psychotropic medication for the management of problem behaviours

in adults with intellectual disabilities. World Psychiatry 2009; 8: 181-186.

4 Tyrer P, Oliver-Africano PC, Ahmed Z, et al Risperidone, haloperidol, and placebo in the treatment of aggressive challenging behaviour in patients with intellectual disability: a randomised controlled trial. Lancet 2008; 371: 57-63.

5 Matson JL, Mahan S. Antipsychotic drug side effects for persons with intellectual disability. Res Dev Disabil 2010; 31: 1570-1576.

\section{About $30 \%$ of people with intellectual} disability have a mental illness, but up to $60 \%$ are prescribed psychotropic medication

Edwards et al

the guidelines are not intended for bariatric surgeons and their teams

McCallum

\section{Guidelines fall short on bariatric surgery}

To THE EDITOR: I am writing in relation to the concerns raised by Dixon in his critique of the Clinical practice guidelines for the management of overweight and obesity from the National Health and Medical Research Council (NHMRC). ${ }^{1}$

When developing guidelines, the NHMRC always includes a consultation phase and Dixon did not raise his concerns during this phase. When his concerns were subsequently brought to NHMRC's attention - just as the guidelines were in the process of being published - the guideline committee agreed to remove examples of nutritional complications as they were open to misinterpretation.

The revised guidelines were issued in October 2013 and Dixon was informed of the amendment. Hence the version of the guidelines cited in Dixon's article does not contain the text with which he took issue in the Journal.

Further, the guidelines are not intended for bariatric surgeons and their teams, as Dixon suggests. The guidelines are specifically targeted at primary care management of overweight and obesity. As such they note that "Individual monitoring and follow-up protocols should be determined by the appropriate specialist team or surgeon, in consultation with the primary care health professionals involved".

The evidence base for the guidelines is documented in the accompanying 656-page systematic review, available on the NHMRC website. $^{2}$

The NHMRC develops guidelines against a rigorous set of standards that include governance by an expert multidisciplinary committee, a documented evidence review process, strict conflict of interest management, 
and independent expert and methodological review.

An integral element is a transparent public consultation process, and the NHMRC urges all clinicians to review guidelines at this stage and respond as appropriate.

John McCallum Head, Research Translation Group

Research Translation Group, National Health and Medical Research Council, Canberra, ACT.

alexis.cooper@nhmrc.gov.au

Competing interests: No relevant disclosures. doi: 10.5694/mjal4.00214

1 Dixon JB. Guidelines fall short on bariatric surgery. Med J Aust 2014; 200: 70.

2 Clinical practice guidelines for the management of overweight and obesity in adults, adolescents and children in Australia Canberra: NHMRC, 2013. http://www.nhmrc. gov.au/guidelines/publications/n57 (accessed Apr 2014).
IN REPLY: I appreciate the opportunity to respond to McCallum's defence of the National Health and Medical Research Council (NHMRC) guideline development process, and appreciate the revisions that were made to the current version. With my general practice background, I understand that the 656-page systematic review will not be considered in clinical practice, but I do know that the text within the guidelines will. And unfortunately that text did not reflect either the established literature or the systematic review. I found the text regarding bariatric surgery flawed throughout, with issues not restricted to nutritional support. There were multiple statements with no evidence base, which of course means they could not be referenced, and two statements where cited references did not support the statement made.

I strongly suggest that the NHMRC carefully reviews its process as described in the letter above. There is limited value in this rigorous process if it delivers a flawed and potentially dangerous outcome. The expert multidisciplinary committee clearly lacked specific expertise in bariatric surgery, and the consultation phase failed to seek appropriate expert advice.

John B Dixon Head of Clinical Obesity Research Vascular and Hypertension - Obesity Research, Baker IDI Heart and Diabetes Institute, Melbourne, VIC.

John.Dixon@bakeridi.edu.au

Competing interests: I have received research funding 
from the NHMRC, including through an NHMRC Senior Research Fellowship. I act as a consultant for Bariatric Advantage, iNova Pharmaceuticals and Nestec Ltd, and have previously consulted for Allergan, Inc. I am on the advisory board for Nestlé Health Science.

doi: 10.5694/mjal4.00294

\section{The case for CBT over antidepressants}

To THE Editor: In her book review, ${ }^{1}$ Wilhelm fails to comment on the central theme of Paul Biegler's The ethical treatment of depression: autonomy through psychotherapy. ${ }^{2}$ Biegler argues that clinicians have a moral duty to promote psychological therapies (including cognitive behaviour therapy) to individuals with uncomplicated depression, over and above antidepressant medications (ADMs). He reasons that patient autonomy and empowerment - surely central concerns for every physician — are most likely achieved with talking therapies, rather than drug treatment.

Wilhelm does not adequately critique Biegler's concern that "... doctors [are] failing on a vast scale to uphold their ethical obligations to patients with [uncomplicated] depression". ${ }^{2}$ Instead, Wilhelm's review focuses on other issues, such as how "... Biegler does not sufficiently discriminate between different types of depression". Biegler does state from the outset that his analysis is restricted to uncomplicated types of mild, moderate or severe depression. However, this is clearly outlined in a reference note rather than being discussed in the text. ${ }^{2}$

Wilhelm is also concerned that Biegler understates the therapeutic role of ADMs in complicated depression. However, Biegler is careful to note, for example, that doctors need to be aware that melancholic depression (to which Wilhelm refers) may be resistant to psychological therapies. ${ }^{2}$ Further, he refers to work concerning the role of stressors in the genesis of melancholic depression, so Wilhelm is incorrect to state that this is not acknowledged in the book.

Although therapy for complicated types of depression is of concern to Wilhelm, it is not the subject of the book. Nor does complicated depression account for the millions of ADMs consumed in Australia annually. Biegler's ethical analysis was motivated by this phenomenon.

P Jane Wilson Scientist and former Tertiary Health Sciences Liaison Librarian

Launceston, TAS.

janewilson.tasmania@westnet.com.au

Competing interests: I am a member of the planning group of Healthy Skepticism, an international non-profit organisation whose main aim is to improve health by reducing harm from misleading drug promotion. doi: 10.5694/mjal3.10716

1 Wilhelm KA. The case for CBT over antidepressants [book review]. Med J Aust 2013; 198: 507.

2 Biegler P. The ethical treatment of depression: autonomy through psychotherapy. Cambridge, Mass: The MIT Press, 2011.

\section{Register4: an Australian web-enabled resource created by the National Breast Cancer Foundation to facilitate and accelerate cancer research}

To THE Editor: Register4 is an online register of Australian men and women that aims to reduce the costs and time involved in recruitment for cancer research studies by matching researchers with willing participants, harnessing the speed and reach of the internet. An initiative of the National Breast Cancer Foundation, Register4 was launched in 2010 and is modelled on the US Army of Women (http:// www.armyofwomen.org) and the Australian Twin Registry. ${ }^{1}$ To date, there are nearly 40000 members (>96\% women) with a broad demographic representation: aged from 18 to over 70 years (most $30-59$ years); residing in all states and territories (most in New South Wales, Victoria and Queensland); and 80\% born in Australia. The membership is highly motivated to participate in research: over $20 \%$ of members are willing to provide DNA samples or participate in a clinical trial, and nearly $15 \%$ are willing to provide a sample of breast tissue.

Data on lifestyle and family health history (including reproductive history, history of breast or other cancers, and chronic illness) have been collected for more than $20 \%$ of members through the online EPI-Q Health and Lifestyle Questionnaire. Of the more than 7300 members who completed the EPI-Q, 20\% have a prior history of breast cancer, and 75\% have no history of any cancer. Other chronic health conditions covered by the questionnaire include asthma ( $20 \%$ of members), high blood pressure $(16 \%)$, and osteoarthritis and osteoporosis (12\%). Over $60 \%$ of participants have never smoked.

To contact Register4 members or access their data, cancer researchers join Register4 as a researcher member, then submit proposals to the Register4 Access Committee for approval. All projects must be fully funded and approved by a human research ethics committee (HREC). The operation of Register4 has HREC approval.

To date, Register4 has been used to recruit participants for 18 cancer research projects, involving nearly 13000 members. Ample and appropriate participants were recruited within days - dramatically faster than conventional recruitment, Hopper et al which typically takes years.

More information about Register4 can be found at the website (https:// www.register4.org.au) or obtained via email (info@register4.org.au) or by telephone (1300 709485).

\section{John L Hopper Director (Research) ${ }^{1}$ \\ Carmel Apicella Senior Research Fellow?}

Alison J Butt Director, Research Investment ${ }^{2}$

1 Centre for Epidemiology and Biostatistics, Melbourne School of Population and Global Health, University of Melbourne, Melbourne, VIC.

2 National Breast Cancer Foundation, Sydney, NSW. alison.butt@nbcf.org.au

Acknowledgements: Seed funding for Register 4 is provided by the National Breast Cancer Foundation. We acknowledge the contributions of Susan Henshall, Sue Carrick, Janet Hiller and members of the EPI-Q Advisory Group in the development of the register and analysis of EPI-Q data

Competing interests: No relevant disclosures. doi: 10.5694/mjal4.00164

1 Hopper JL, Foley DL, White PA, Pollaers V. Australian Twin Registry: 30 years of progress. Twin Res Hum Genet 2013; 16: 34-42.

\section{A quack heard around the world}

To THE EDITOR: I note with interest Best's article suggesting that medical involvement in sport and training should not focus only on the elite athlete. ${ }^{1}$ I agree wholeheartedly 
with this premise. Best informs us that a sports medicine training facility at Falls Creek would "combine the current medical service and teaching arrangements with a new model for year-round sports training in a'clean' environment".

The Australasian College of Sports Physicians (ACSP) has had a full-time, 4-year advanced training program in sport and exercise medicine since 1992. Sport and exercise medicine is recognised as a medical specialty by the Australian Medical Council (AMC), and the ACSP training program is an AMC-accredited specialist training program. Best's article could easily be interpreted as suggesting that current training in sports medicine lacks ethical content and is confined to the concerns of the elite athlete. The vast majority of patients seen by sport and exercise medicine physicians have no involvement in elite sport, and many would not consider themselves "athletes" in any sense of the word. The practice of sport and exercise medicine focuses on removing obstacles to physical activity for individuals of all ages and exercise capacities.

The ACSP training program has a heavy emphasis on ethical practice, evidence-based nutrition, physical activity as a therapeutic intervention, and antidoping education. While it is true that ACSP Fellows are strongly represented in sports medicine leadership positions in Australia and New Zealand, most ACSP Fellows (> 80\%) draw no significant revenue stream from high-performance (elite) sport.
David Hughes Chief Medical Officer, and Immediate Past President $^{2}$

1 Australian Institute of Sport, Canberra, ACT.

2 Australasian College of Sports Physicians, Melbourne, VIC.

david.hughes@ausport.gov.au

Competing interests: No relevant disclosures.

doi: 10.5694/mjal4.00300

1 Best J. A quack heard around the world. Med J Aust 2013; 199: 797.

IN REPLY: I thank Hughes for his comments. The message I tried to convey in my article ${ }^{1}$ is that it is important, with a relatively new specialty such as sports medicine, to have the opportunity to work with other medical specialties, health professionals and the community to establish a multipurpose facility where transparency of effort and integration of service, training and research can occur. I understand the University of Melbourne may be hosting a forum later this year to explore this matter further. There is thus no disagreement with Hughes.

If there was a perception that sports physicians are only concerned with elite sport and thus lack ethical underpinning, I regret that implication could be drawn from my article. However, as an observer of the health scene, I address as much as I can perceive.

It is refreshing, at a time when there is such uncertainty about the acceptable limits of performance enhancement, that sports physicians should have a strong voice - and for this Hughes must be commended.

John B Best Director of Clinical Training

Murray to the Mountains Intern Training Program, Sydney, NSW.

jbbest@iimetro.com.au

The vast

majority of

patients

seen by sport

and exercise

medicine

physicians have no involvement in elite sport

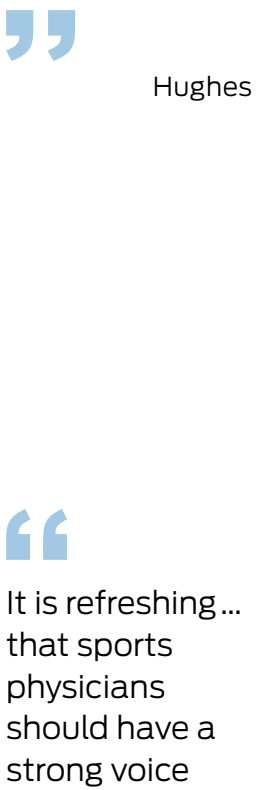

Best
Competing interests: No relevant disclosures. doi: 10.5694/mjal4.00325

1 Best J. A quack heard around the world. Med J Aust 2013; 199: 797.

\section{CORRESPONDENTS}

The MJA welcomes letters on new topics (no longer than 350 words) or commenting on an MJA article (no longer than 250 words). All letters should have no more than three authors. Comments about MJA articles should be submitted within 1 month of that article's publication and should be given the same title as the article. Letters should be appropriately referenced in the same style and format as other MJA articles, with no more than 5 references. All research letters are peer reviewed, and other letters may also be peer reviewed. All letters are subject to editing. Proofs will not normally be supplied unless significant changes are made.

(See https://www.mja.com.au/ journal/mja-instructions-authors)

\section{CORRECTION}

Incorrect references: In"The newer contraceptive pills and venous thromboembolism risk" in the 21 April 2014 issue of the Journal (Med J Aust 2014; 200: 376-377), there was an error in the reference numbers shown in the Box. In three instances where reference 4 was cited, this should have been reference 3 instead. 